\title{
Erratum: Efficiency versus instability in plasma accelerators [Phys. Rev. Accel. Beams 20, 121301 (2017)]
}

Valeri Lebedev, Alexey Burov, and Sergei Nagaitsev

(Q) (Received 2 May 2018; published 23 May 2018)

DOI: 10.1103/PhysRevAccelBeams.21.059901

There are 3 typos in Eq. (24) of this paper. The correct equation is shown below:

$$
\begin{aligned}
r_{b}(\xi) & =\sqrt{r_{t 2}{ }^{2}-r_{t 2} \xi \sqrt{2\left(\frac{R_{b}{ }^{4}}{r_{t 2}{ }^{4}}-1\right)}}, \\
L_{t} & =\frac{r_{t 2}{ }^{2}-r_{t 1}{ }^{2}}{r_{t 2}}\left(2\left(\frac{R_{b}{ }^{4}}{r_{t 2}{ }^{4}}-1\right)\right)^{-1 / 2}
\end{aligned}
$$

The results and conclusions of the article are not effected.

Published by the American Physical Society under the terms of the Creative Commons Attribution 4.0 International license. Further distribution of this work must maintain attribution to the author(s) and the published articles title, journal citation, and DOI. 